\title{
Design Multilayer Antireflection Coatings for Terrestrial Solar Cells
}

\author{
Feng Zhan, ${ }^{1}$ Zhipeng Li, ${ }^{2}$ Xiaoming Shen, ${ }^{1}$ Huan He, ${ }^{1}$ and Jianmin Zeng ${ }^{1}$ \\ ${ }^{1}$ The Key Laboratory of Nonferrous Metal Materials and New Processing Technology of Ministry of Education, \\ Guangxi University, Nanning 530004, China \\ ${ }^{2}$ Department of Physics and Astronomy, University of North Carolina, Chapel Hill, NC 27599, USA
}

Correspondence should be addressed to Xiaoming Shen; shenxiaoming@sina.com

Received 31 August 2013; Accepted 19 November 2013; Published 28 January 2014

Academic Editors: E. Liu, A. Meghea, H. Ruda, and Z. Yang

Copyright (c) 2014 Feng Zhan et al. This is an open access article distributed under the Creative Commons Attribution License, which permits unrestricted use, distribution, and reproduction in any medium, provided the original work is properly cited.

In order to analyze the influence of methods to design antireflection coatings (ARCs) on reflectivity of broadband solar cells, we provide detailed analyses about the ARC coupled with a window layer and the refractive index dispersion effect of each layer. By multidimensional matrix data simulation, two methods were employed to measure the composite reflection of a SiO $\mathrm{O}_{2} / \mathrm{ZnS}$ doublelayer ARC within the spectral ranges of 300-870 $\mathrm{nm}$ (dual junction) and 300-1850 nm (triple junction) under AM1.5 solar radiation. A comparison study, between the results obtained from the commonly used weighted average reflectance method (WAR) and that from the introduced effective average reflectance method (EAR), shows that the optimization of ARC by EAR method is convenient and feasible.

\section{Introduction}

Reflective loss of the incident light on the device surface is an important factor that affects efficiency of solar cell (SC). Design of antireflection structure has become a key factor in SC fabrication [1-7]. For III-V tandem SCs, a proper group of transparent materials are deposited on the SC surface, leading to the formation of antireflection coatings (ARCs) $[7,8]$. Consequently, the reflective loss of the incident lights would be minimized and the SCs work in a spectral range with higher efficiency. Therefore, broadband ARCs are essential for SCs operating at a broad spectrum.

Generally, there are various types of broadband ARC. For instance, flat multilayer ARCs can be double, triple, or quadruple layer. Many studies have shown that the performance of a single layer coating is not satisfying due to its narrow working spectral range. Double-, triple-, or even multiple-layer ARCs [7, 9-11] have better performance when referring to broadband SCs. Double-layer ARCs are commonly used because of their simple fabrication process and low cost. In this paper, the principle and method of antireflective films were introduced. A multidimensional matrix for the refractive index dispersion effect of each layer was used to simulate the reflectivity of several optical film systems. An effective average reflectance $R_{e}$ method (EAR) simplified from the commonly used weighted average reflectance $R_{w}$ method (WAR) was also utilized to design ARCs. The optimizations of ARCs in the dual- and triplejunction SCs by two methods were compared and analyzed. Accordingly, it demonstrates that optimizing ARC by minimizing $R_{e}$ is more convenient under the AM1.5 conditions. The models for optimization of multilayer ARC are presented in the following section, and their differences from a typical double-layer ARC are discussed in detail thereafter.

\section{Methodology}

The reflectivity at normal incidence of a $\mathrm{SiO}_{2} / \mathrm{ZnS}$ doublelayer antireflection coating (ARC) on an $\mathrm{Al}_{0.5} \mathrm{In}_{0.5} \mathrm{P}$ window layer is typically modeled in front of a $\mathrm{Ga}_{0.5} \mathrm{In}_{0.5} \mathrm{P}$ top cell. This approach is based on previously measured optical parameters for materials such as $\mathrm{Al}_{0.5} \mathrm{In}_{0.5} \mathrm{P}$ and $\mathrm{Ga}_{0.5} \mathrm{In}_{0.5} \mathrm{P}$ [12] , as well as others [12-14] used as ARCs. The optical parameters of any composition of ARC are generally determined by cubic interpolation. We adopted the transfermatrix method to model the reflectance of the system, as this 


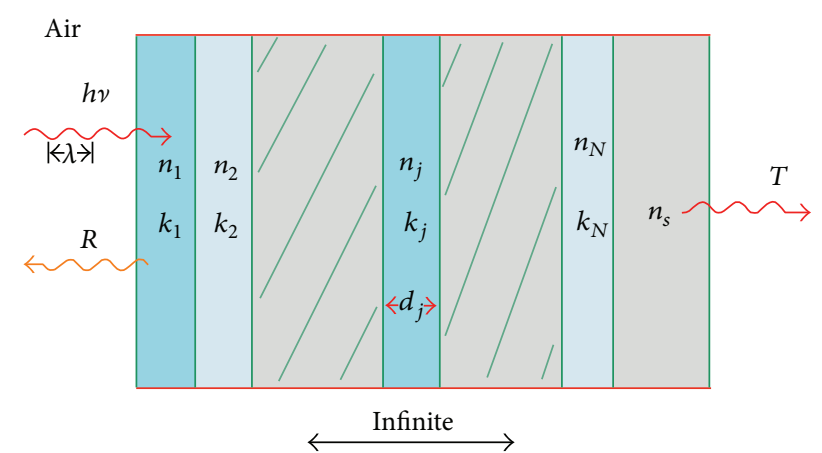

FIGURE 1: Schematic diagram of the optical model for stacked films.

approach can be used to analyze multilayer films of varying thickness, refractive indices $(n)$, and extinction coefficients $(k)$ on a substrate.

Optical interference matrix is an effective way to calculate reflectivity of film. To allow the situation that the incident angle of light is zero degree, considering the optical thin film system of $N$ layers prepared on the substrate as shown in Figure $1, n_{j}$ is the refractive index and $k_{j}$ is the extinction coefficient, $d_{j}$ is the thickness in each layer, respectively, and $n_{0}$ is refractive index of air $\left(n_{0}=1\right)$. According to the refractive index and thickness of each layer, interference matrix of each layer can be determined. A characteristic matrix formulation of the film system is obtained by multiplying interference matrix of each layer [15]:

$$
\begin{aligned}
{\left[\frac{B}{C}\right] } & =\left\{\prod_{j=1}^{N}\left[\begin{array}{cc}
\cos \delta_{j} & \frac{i \sin \delta_{j}}{n_{j}} \\
i n_{j} \sin \delta_{j} & \cos \delta_{j}
\end{array}\right]\right\}\left[\begin{array}{c}
1 \\
n_{s}
\end{array}\right] \\
& =\left[\begin{array}{ll}
M_{11} & M_{12} \\
M_{21} & M_{22}
\end{array}\right]\left[\begin{array}{c}
1 \\
n_{s}
\end{array}\right],
\end{aligned}
$$

where $\delta_{j}$ is the effective optical thickness of the layer at a given wavelength. The $2 \delta_{j}$ is equal to the phase difference of two adjacent coherent light beams. $Y=C / B$ is the optical admittance. The reflectivity $R$ of the whole film system is expressed as

$$
R=|r|^{2}=\left|\frac{n_{0}-Y}{n_{0}+Y}\right|^{2}
$$

The solar spectrum spans a broad range of wavelengths. To enable more incident light to enter the SC, the internal quantum efficiency of the material and the sun's spectral characteristics should all be considered during the design of ARCs. The weighted average reflectivity within the entire spectrum can be calculated by the incident photon flux $F(\lambda)$ [16], the internal quantum efficiency (IQE) of the SC $Q(\lambda)$ $[17,18]$, and the reflectivity of monochromatic light $R(\lambda)[19]$ :

$$
R_{w}=\frac{\int_{\lambda_{1}}^{\lambda_{2}} F(\lambda) R(\lambda) Q(\lambda) d \lambda}{\int_{\lambda_{1}}^{\lambda_{2}} F(\lambda) Q(\lambda) d \lambda},
$$

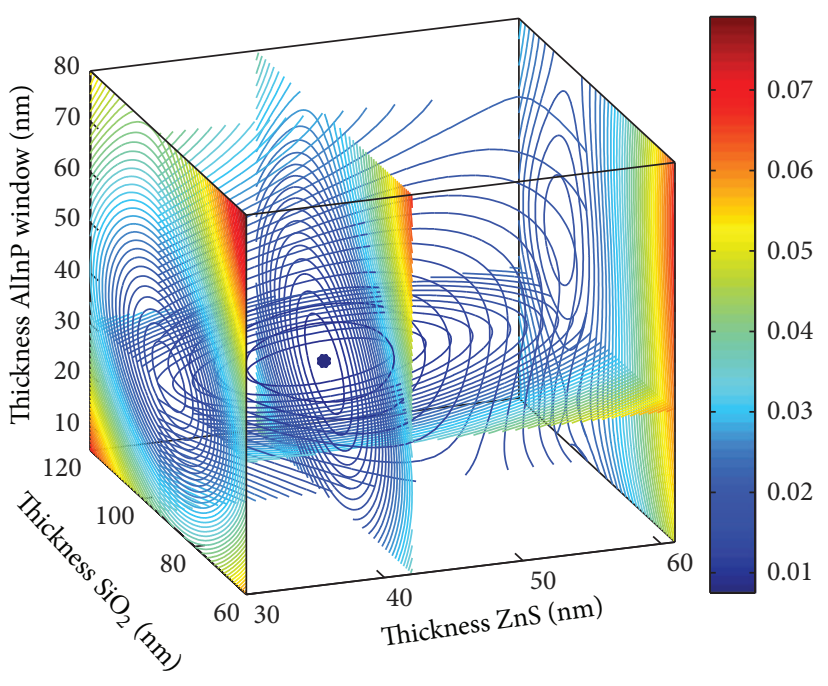

FIGURE 2: $\mathrm{SiO}_{2} / \mathrm{ZnS}$ ARC $R_{e}$ versus films thickness.

where $\lambda_{1}$ represents the lower limit of spectral response and $\lambda_{2}$ represents the upper limit.

Considering that there are minor differences in IQEs among different monochromatic light in practical applications, we set IQEs equal to induce the average effective reflectance $R_{e}$ for a convenient design [20]:

$$
R_{e}=\frac{\int_{\lambda_{1}}^{\lambda_{2}} F(\lambda) R(\lambda) d \lambda}{\int_{\lambda_{1}}^{\lambda_{2}} F(\lambda) d \lambda} .
$$

\section{Results and Discussion}

In this section, we will discuss the minimization results obtained for the weighted average reflectance and effective average reflectance of the $\mathrm{SiO}_{2} / \mathrm{ZnS}$ double-layer structure on double- and triple-junction SCs under AM1.5 conditions.

3.1. Dual Junction Solar Cell $(300-870 \mathrm{~nm})$. The fourdimensional images shown in Figures 2 and 3 depict the optimal parameters of the $\mathrm{SiO}_{2} / \mathrm{ZnS}$ ARC for the $\mathrm{Ga}_{0.5} \operatorname{In}_{0.5} \mathrm{P} / \mathrm{GaAs}$ double-junction SC under AM1.5 conditions. The reflectivity curves of $\mathrm{SiO}_{2} / \mathrm{ZnS}$ films optimized by $R_{e}$ and $R_{w}$ are shown in Figure 4 . The $\mathrm{SiO}_{2} / \mathrm{ZnS}$ ARC parameters for the double-junction SC optimized by different methods are summarized in Table 1.

Those optimized by $R_{e}$ and $R_{w}$ exhibited minimal differences (see in Table 1), with the change in thickness values being less than $2 \mathrm{~nm}$ and the reflectivities in the spectral range of $400-700 \mathrm{~nm}$ remaining almost unchanged, that these reflectivities are the lowest where the solar photon flux is mainly distributed (see Figure 4). These results indicated that optimizing the ARC by minimizing the effective average reflectance $R_{e}$ for double-junction SC is feasible.

3.2. Triple Junction Solar Cell $(300-1850 \mathrm{~nm})$. The fourdimensional images shown in Figures 5 and 6 depict 
TABLE 1: Comparison of parameters of $\mathrm{SiO}_{2} / \mathrm{ZnS}$ ARC for dual junction SC optimized by different methods.

\begin{tabular}{lccc}
\hline & Optimized by EAR method & Optimized by WAR method & Change \\
\hline $\mathrm{SiO}_{2}$ thickness $(\mathrm{nm})$ & 94 & 95 & $-1.05 \%$ \\
$\mathrm{ZnS}$ thickness $(\mathrm{nm})$ & 42 & 43 & $-2.32 \%$ \\
Window layer thickness $(\mathrm{nm})$ & 31 & 31 & $0 \%$ \\
\hline Average reflectance $\left(R_{e} / R_{w}\right)$ & $0.75 \%$ & $0.68 \%$ & $0.07 \%$ \\
\hline
\end{tabular}

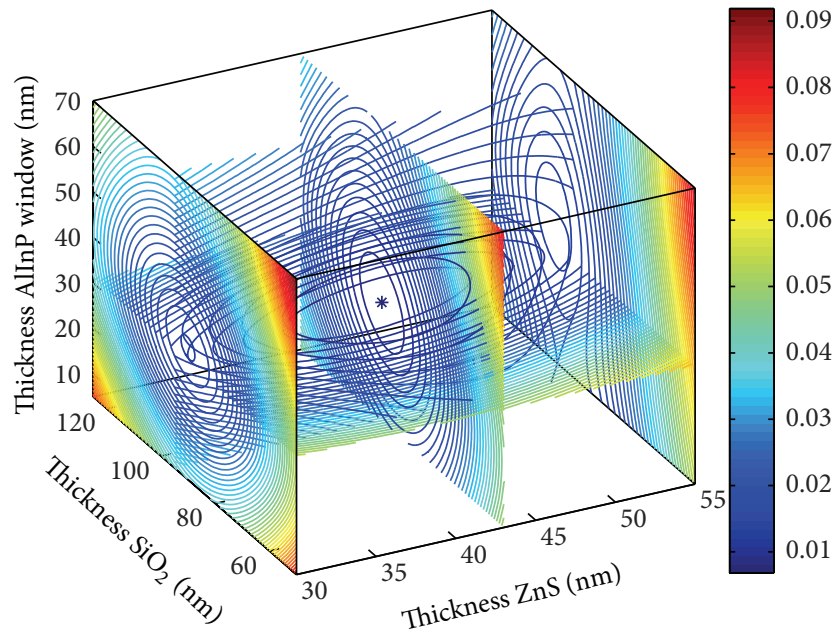

FIGURE 3: $\mathrm{SiO}_{2} / \mathrm{ZnS}$ ARC $R_{w}$ versus films thickness.

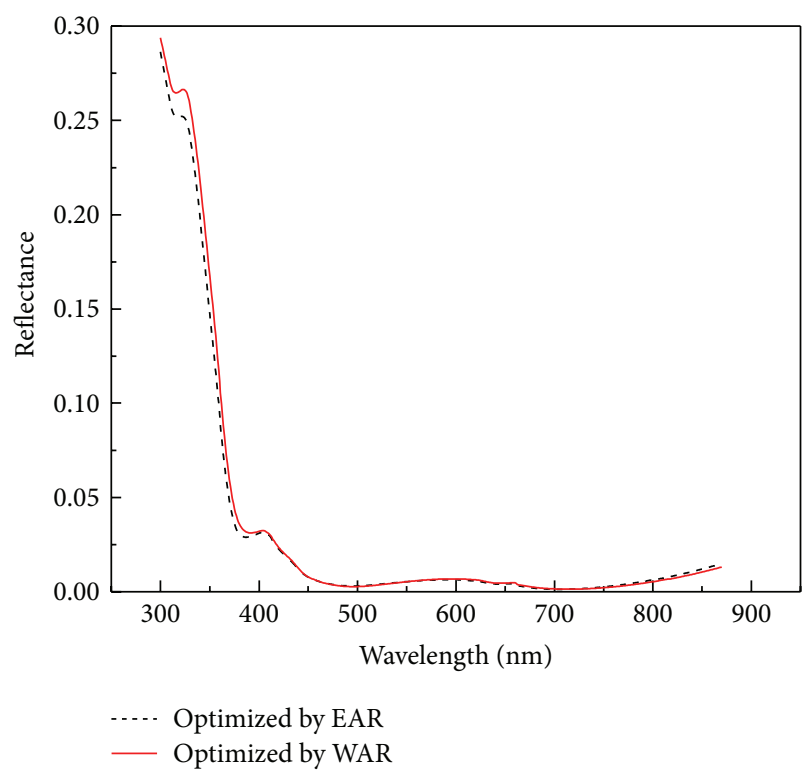

FIgURE 4: Optimal $\mathrm{SiO}_{2} / \mathrm{ZnS}$ ARC reflectivity versus wavelength.

the optimal parameters of the $\mathrm{SiO}_{2} / \mathrm{ZnS} \mathrm{ARC}$ for the $\mathrm{Ga}_{0.5} \mathrm{In}_{0.5} \mathrm{P} / \mathrm{GaAs} / \mathrm{Ge}$ triple-junction SC under AM1.5 conditions. The reflectivity curves of $\mathrm{SiO}_{2} / \mathrm{ZnS}$ films optimized by $R_{e}$ and $R_{w}$ are shown in Figure 7. The $\mathrm{SiO}_{2} / \mathrm{ZnS}$ ARC parameters for the triple-junction SC optimized by different methods are summarized in Table 2.

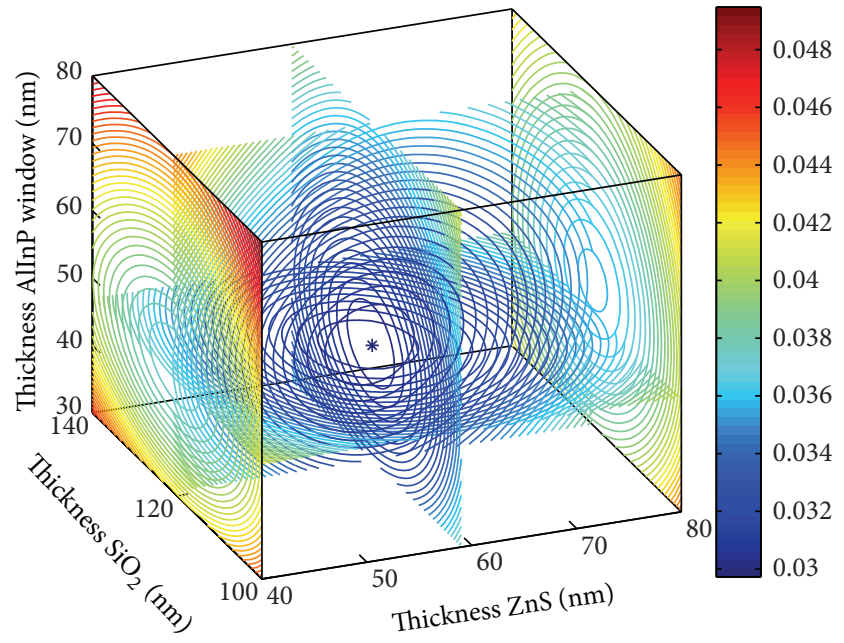

FIGURE 5: $\mathrm{SiO}_{2} / \mathrm{ZnS}$ ARC $R_{e}$ versus films thickness.

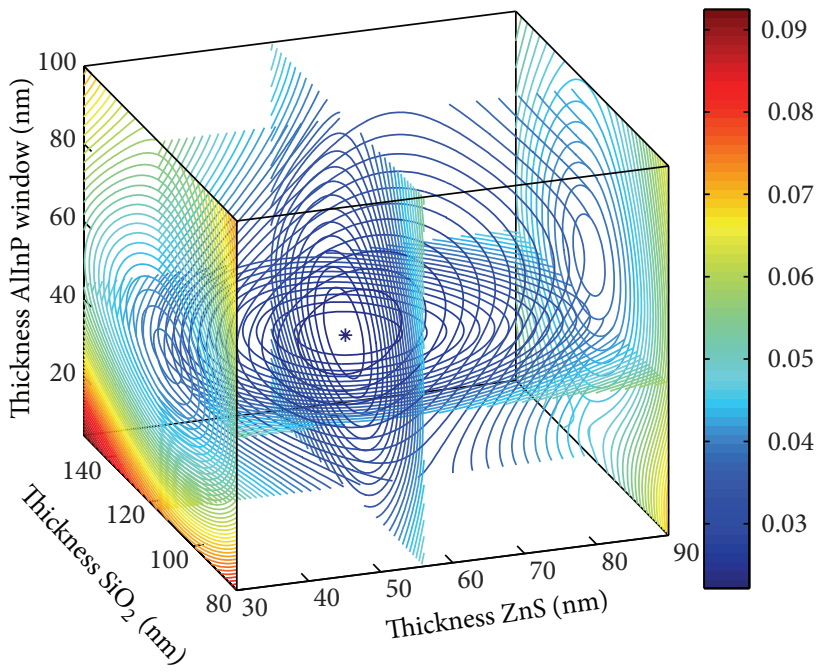

Figure 6: $\mathrm{SiO}_{2} / \mathrm{ZnS}$ ARC $R_{w}$ versus films thickness.

Those optimized by WAR and EAR methods also exhibited minimal differences in triple junction SC (see in Table 2), with the change in thickness values being less than $2 \mathrm{~nm}$ and the reflectivities in the spectral range of $400-700 \mathrm{~nm}$ remaining almost unchanged. The reflectivities are properly the lowest where the solar photon flux is mainly distributed (see Figure 7). These results indicated that optimizing the ARC by minimizing the effective average reflectance $R_{e}$ for double-junction SC is feasible. 
TABLE 2: Comparison of parameters of $\mathrm{SiO}_{2} / \mathrm{ZnS}$ ARC for triple junction SC optimized by different methods.

\begin{tabular}{lccc}
\hline & Optimized by EAR method & Optimized by WAR method & Change \\
\hline $\mathrm{SiO}_{2}$ thickness $(\mathrm{nm})$ & 121 & 116 & $4.31 \%$ \\
$\mathrm{ZnS}$ thickness $(\mathrm{nm})$ & 59 & 56 & $5.36 \%$ \\
Window layer thickness $(\mathrm{nm})$ & 47 & 44 & $6.82 \%$ \\
\hline Average reflectance $\left(R_{e} / R_{w}\right)$ & $2.97 \%$ & $2.21 \%$ & $0.76 \%$ \\
\hline
\end{tabular}

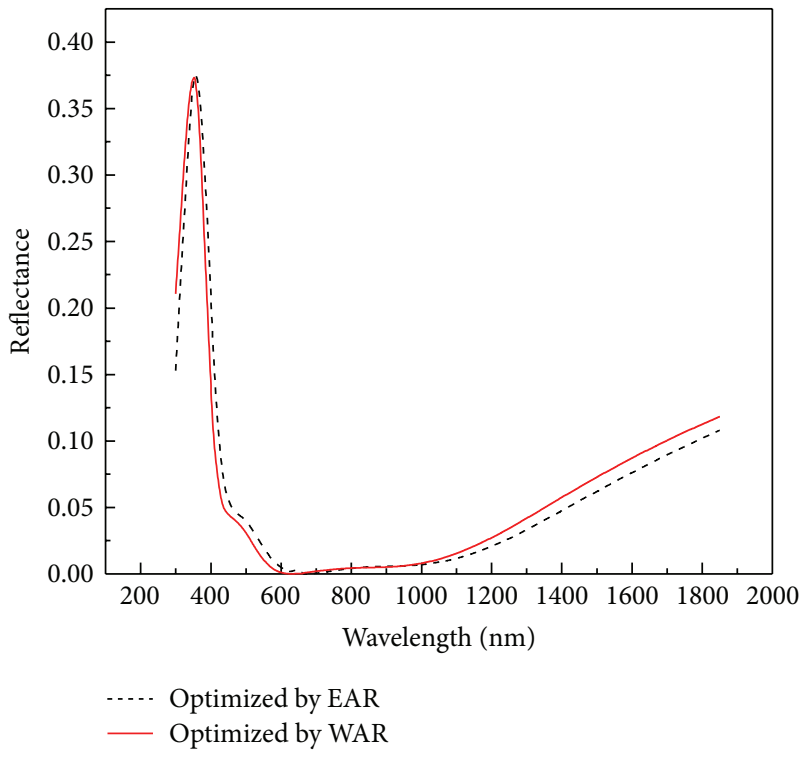

FIgURE 7: Optimal $\mathrm{SiO}_{2} / \mathrm{ZnS}$ ARC reflectivity versus wavelength.

\section{Summary}

To summarize, this study represents the theoretical optimization of the $\mathrm{SiO}_{2} / \mathrm{ZnS}$ double-layer $\mathrm{ARC}$ on the $\mathrm{Al}_{0.5} \mathrm{In}_{0.5} \mathrm{P}$ window layer for double- and triple-junction SCs under AM1.5 condition. It demonstrated that there are no considerable differences in the final optimal ARC parameters by WAR method and EAR method. For the double-junction SC, the changes in ARC thickness and average reflectivity were determined to be less than $2 \mathrm{~nm}$ and $0.07 \%$, respectively. On the other hand, for the triple-junction SC, the corresponding values obtained were less than $6 \mathrm{~nm}$ and $0.76 \%$, respectively. These slight changes in the parameters are acceptable. Therefore, optimizing ARCs by minimizing the $R_{e}$ introduced, instead of $R_{w}$, as is commonly used, is thus a viable technique under AM1.5 condition.

\section{Conflict of Interests}

The authors declare that there is no conflict of interests regarding the publication of this paper.

\section{Acknowledgments}

This work has been sponsored by the Scientific Research Foundation of Guangxi University (Gant no. XBZ120145), the Natural Science Foundation of Guangxi of China (Grant no.
2013GXNSFBA019019), the Key Project of Guangxi Science and Technology Lab Center (Gant no. LGZX201105), the National Natural Science Foundation of China (Grant no. 11364003), and the Open Fund of Ministry-province jointlyconstructed Cultivation Base for State Key Laboratory of Processing for Non-ferrous Metal and Featured Materials, Guangxi Zhuang Autonomous Region (Gant no. GXKFJ12$01)$.

\section{References}

[1] A. B. Christiansen, J. Clausen, N. A. Mortensen, and A. Kristensen, "Minimizing scattering from antireflective surfaces replicated from low-aspect-ratio black silicon," Applied Physics Letters, vol. 101, no. 13, Article ID 131902, 2012.

[2] M. D. Kelzenberg, S. W. Boettcher, J. A. Petykiewicz et al., "Enhanced absorption and carrier collection in Si wire arrays for photovoltaic applications," Nature Materials, vol. 9, pp. 239244, 2010.

[3] E. Garnett and P. Yang, "Light trapping in silicon nanowire solar cells," Nano Letters, vol. 10, no. 3, pp. 1082-1087, 2010.

[4] D. Lehr, M. Helgert, M. Sundermann et al., "Simulating different manufactured antireflective sub-wavelength structures considering the influence of local topographic variations," Optics Express, vol. 18, no. 23, pp. 23878-23890, 2010.

[5] Q. G. Du, C. H. Kam, H. V. Demir, H. Y. Yu, and X. W. Sun, "Broadband absorption enhancement in randomly positioned silicon nanowire arrays for solar cell applications," Optics Letters, vol. 36, no. 10, pp. 1884-1886, 2011.

[6] W. T. Dai, D. Yap, and G. Chen, "Wideband enhancement of infrared absorption in a direct band-gap semiconductor by using nonabsorptive pyramids," Optics Express, vol. 20, 4, pp. A519-A529, 2012.

[7] F. Zhan, H.-L. Wang, J.-F. He et al., "Multilayer antireflection coating for triple junction solar cells," Chinese Physics Letters, vol. 28, no. 4, Article ID 047802, 2011.

[8] M. A. Green, Solar Cells: Operating Principles, Technology, and System Applications, Prentice-Hall, Englewood Cliffs, NJ, USA, 1982.

[9] B. S. Richards, "Single-material $\mathrm{TiO}_{2}$ double-layer antireflection coatings," Solar Energy Materials and Solar Cells, vol. 79, no. 3, pp. 369-390, 2003.

[10] C.-H. Chang, L. Waller, and G. Barbastathis, "Design and optimization of broadband wide-angle antireflection structures for binary diffractive optics," Optics Letters, vol. 35, no. 7, pp. 907-909, 2010.

[11] F. Zhan, J.-F. He, X.-J. Shang et al., "An effective reflectance method for designing broadband antireflection films coupled with solar cells," Chinese Physics B, vol. 21, no. 3, Article ID 037802, 2012. 
[12] S. Adachi, "Optical dispersion relations for GaP, GaAs, GaSb, InP, InAs, InSb, $A 1_{x} G a_{1-x}$ As, and $I n_{1-x} G a_{x} A s_{y} P_{1-y}$ " Journal of Applied Physics, vol. 66, no. 12, pp. 6030-6040, 1989.

[13] S. Adachi, "Optical properties of $\operatorname{In}_{1-x} G a_{x} A s_{y} P_{1-y}$ alloys," Physical Review B, vol. 39, no. 17, pp. 12612-12621, 1989.

[14] E. D. Palik, Handbook of Optical Constant of Solids, Academic Press, New York, NY, USA, 1st edition, 1997.

[15] H. A. Macleod, Thin Film Optical Filters, Institute of Physics, London, UK, 3rd edition, 2001.

[16] K. L. Chopra and S. R. Das, Thin Film Solar Cells, Plenum, New York, NY, USA, 1983.

[17] S. P. Philipps, M. Hermle, G. Létay, F. Dimroth, B. M. George, and A. W. Bett, "Calibrated numerical model of a GaInP-GaAs dual-junction solar cell," Physica Status Solidi, vol. 2, no. 4, pp. 166-168, 2008.

[18] C. E. Valdivia, E. Desfonds, D. Masson et al., "Optimization of antireflection coating design for multi-junction solar cells and concentrator systems," in Photonics North 2008, vol. 7099 of Proceedings of SPIE, Montréal, Canada, June 2008.

[19] J. Zhao and M. A. Green, "Optimized antireflection coatings for high-efficiency silicon solar cells," IEEE Transactions on Electron Devices, vol. 38, no. 8, pp. 1925-1934, 1991.

[20] H. R. Yuan, X. Xiang, X. Chang, and D. Lu, "Double layer antireflection coating on $\mathrm{Al}_{0.8} \mathrm{Ga}_{0.2} \mathrm{As} / \mathrm{GaAs}$ solar cells," Acta Energiae Solaris Sinica, vol. 21, no. 4, pp. 371-378, 2000 (Chinese). 

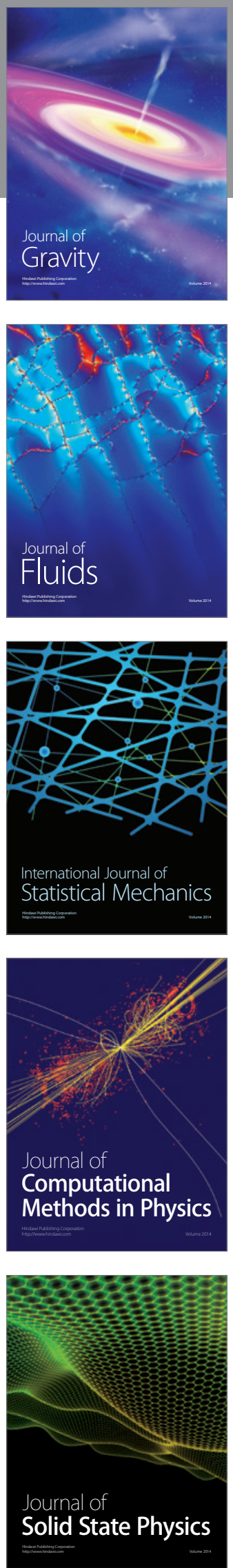

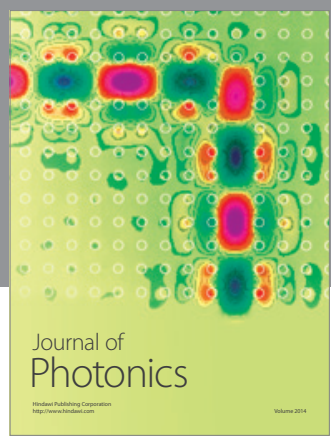

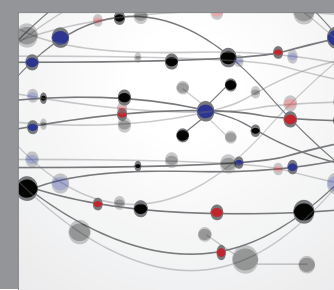

The Scientific World Journal

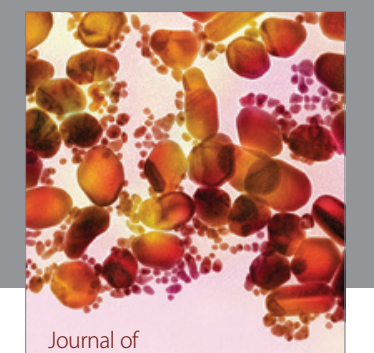

Soft Matter
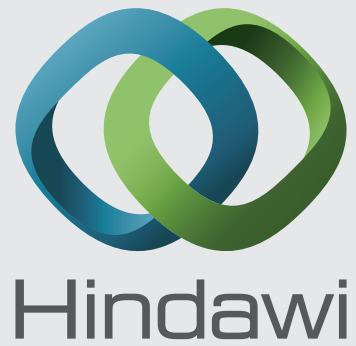

Submit your manuscripts at

http://www.hindawi.com
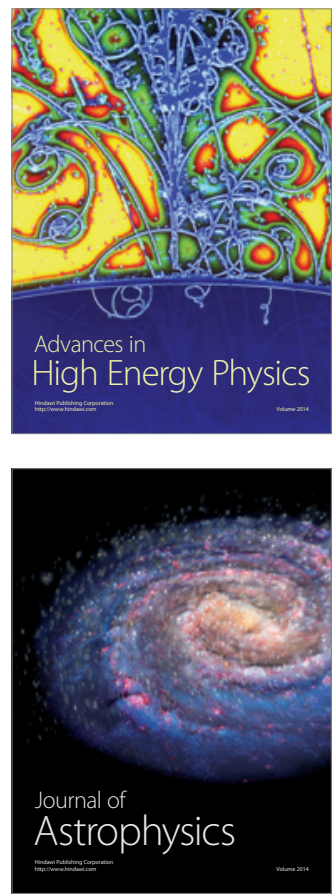
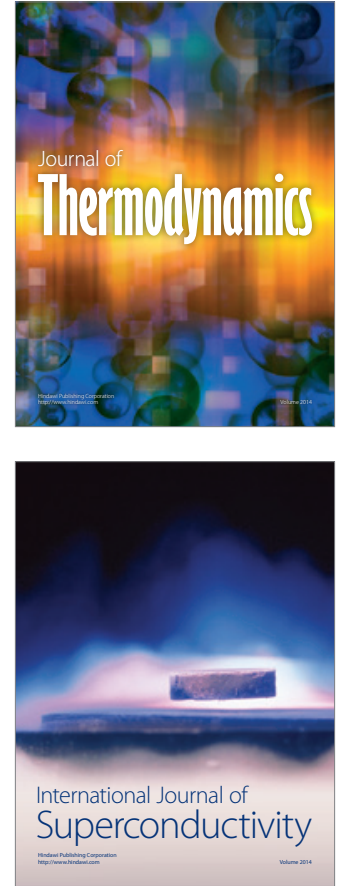
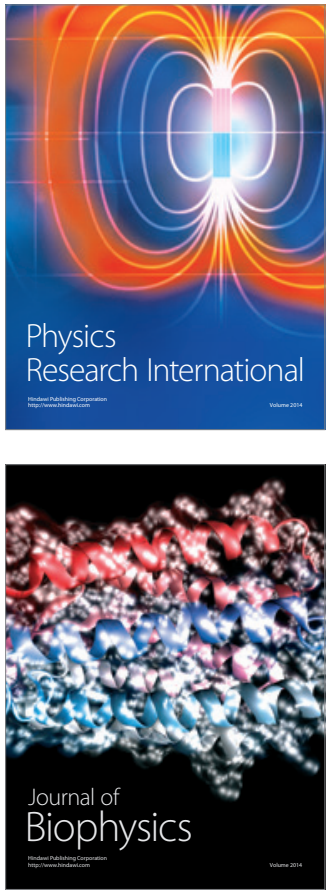
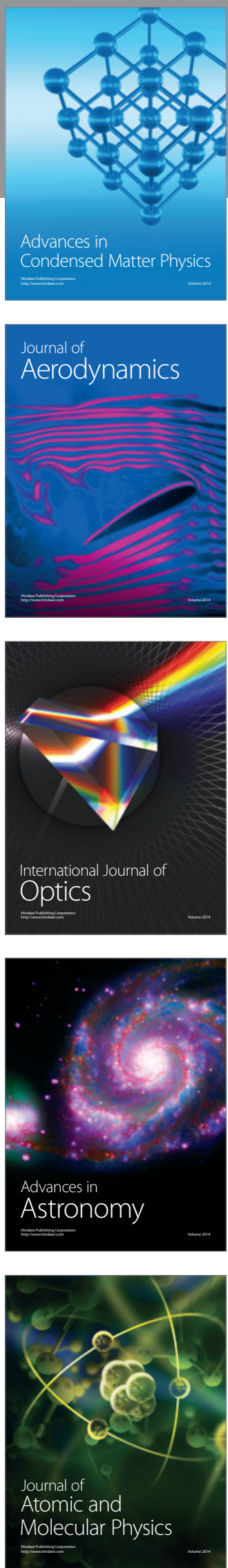